\title{
Anomalous left coronary artery arising from the left pulmonary artery, aortic coarctation, and a large ventricular septal defect
}

\author{
John Santosh Kumar Murala, MBBS, MS, MCh, ${ }^{a}$ Steven Cooper, MBChB, FRACP, \\ Barry Duffy, AM, MBBS, FRACP, FJFICH, ${ }^{c}$ Nizam Matbah, MBBCh, MMED, ${ }^{b}$ Elizabeth Argent, MBBS, FRACP, ${ }^{d}$ \\ and Graham Nunn, MBBS (Hon), FRACS, AM, ${ }^{a}$ Sydney, Australia
}

W e describe a case of large ventricular septal defect (VSD), coarctation of the aorta, anomalous left coronary artery arising from the left pulmonary artery (ALCALPA), and congenital diaphragmatic hernia that was successfully managed surgically. Literature search revealed no report of a similar condition.

\section{Clinical Summary}

A baby girl was found to have a right-sided diaphragmatic hernia antenatally. Fetal cardiac ultrasonography suggested perimembranous VSD. These diagnoses were confirmed postnatally, and the hernia was repaired. In addition to the VSD, the baby was found to have an aortic coarctation and pulmonary hypertension (PHT) out of proportion to the size of the VSD. Medical treatment failed to control symptoms of respiratory distress, and surgical intervention to repair the VSD and coarctation was planned. Preoperative cardiac catheterization was performed to assess PHT and to confirm the severity of the coarctation. This confirmed a large perimembranous VSD with large left-to-right shunt and balanced ventricular pressures, moderate coarctation of the aorta with isthmic hypoplasia, and the unexpected finding of an ALCALPA (Figures 1 and 2); this last finding had not been identified echocardiographically. The baby also had a patent foramen ovale and small patent ductus arteriosus. There was no coexisting mitral regurgitation.

A single-stage operation was performed through a median sternotomy: arterial cannulas were placed in both the ascending aorta and the main pulmonary artery and the venous cannula in both cavae. Cardioplegia was given after clamping both the aorta and the main pulmonary artery and snaring both branch pulmonary arteries. The left coronary artery (LCA) was excised from the left pulmonary artery (LPA) as a button. It was then brought posterior to the main pulmonary artery near the sinotubular junction on the left posterior aspect of the ascending aorta and anastomosed there. The defect in the LPA was repaired with a pericardial patch.

From the Departments of Cardiothoracic Surgery, ${ }^{\mathrm{a}}$ Paediatric Cardiology, ${ }^{\mathrm{b}}$ Children's Intensive Care, ${ }^{\mathrm{c}}$ and General Paediatrics ${ }^{\mathrm{d}}$ of Sydney Children's Hospital, Randwick, New South Wales, Australia.

Received for publication Oct 2, 2005; accepted for publication Oct 18, 2005.

Address for reprints: Graham Nunn, MBBS (Hon), FRACS, AM, Department of Cardiothoracic Surgery, Sydney Children's Hospital, High Street, Randwick, New South Wales, Australia 2031 (E-mail: gnunn@tpg.com.au).

J Thorac Cardiovasc Surg 2006;131:911-2

$0022-5223 / \$ 32.00$

Copyright (C) 2006 by The American Association for Thoracic Surgery doi:10.1016/j.jtcvs.2005.10.051

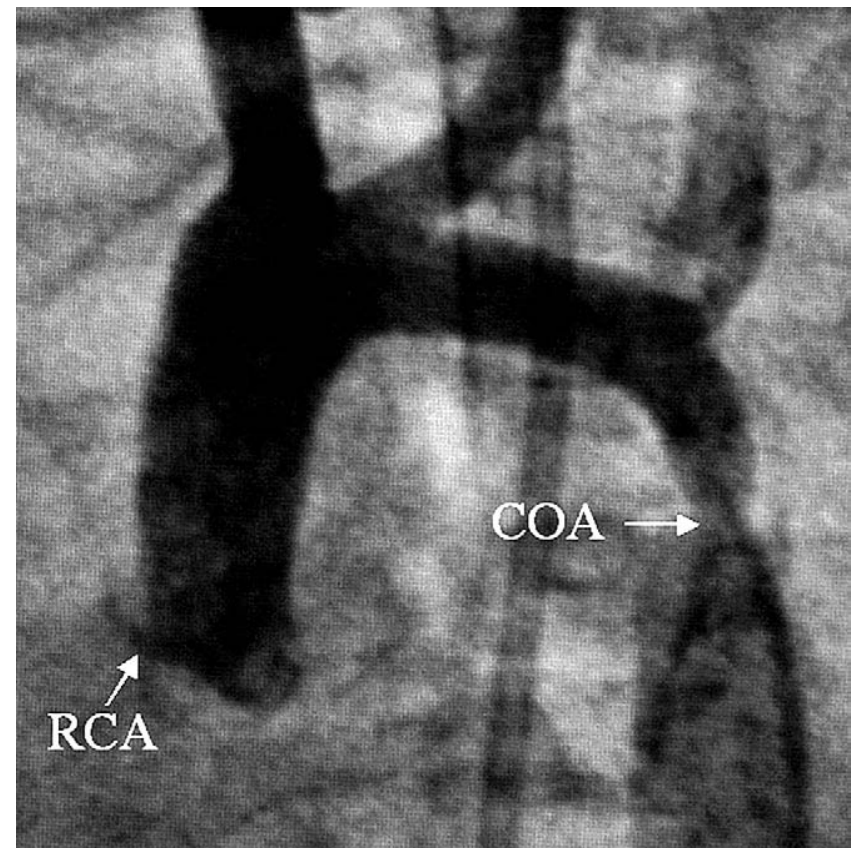

Figure 1. Aortogram showing single right coronary artery (RCA) from the right aortic cusp and coarctation of the aorta (COA).

Later the cavae were snared, and the VSD and the patent foramen ovale were closed. The crossclamp was released, the ductus was divided, and the coarctation segment was excised, and end-to-end anastomosis was performed. Postoperatively, sternal closure was delayed for 3 days.

The patient had a stormy course in intensive care, which was complicated by low cardiac output, junctional ectopic tachycardia, and episodes of ventricular tachycardia. Initial parameters (electrocardiography) and troponin levels suggested myocardial ischemia, but these soon resolved, and the flow in the reimplanted LCA was shown to be excellent on color Doppler echocardiography. Left ventricular function was well maintained. After 48 hours, her cardiac function stabilized, but her course was complicated by uncontrolled PHT. She was treated with hyperventilation, high fraction of inspired oxygen, and alkalinization, as well as nitric oxide, prostacyclin, bosentan, and sildenafil. She was ventilated for 6 weeks, and eventually her condition improved. Echocardiography showed trivial tricuspid regurgitation with mild PHT (one third of the systemic pressures), normal ventricular function, no residual coarctation or VSD, and good flow in the LCA. Endoscopy revealed improvement in bronchomalacia. She 


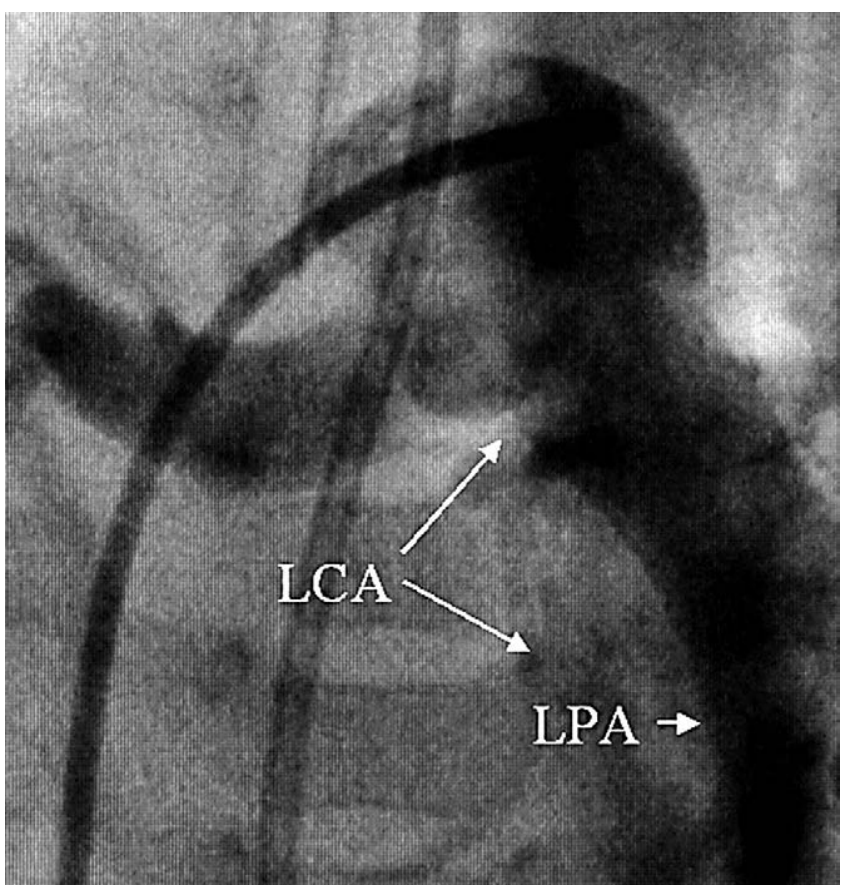

Figure 2. Pulmonary artery injection showing the origin of the left coronary artery (LCA) from the proximal part of the left pulmonary artery (LPA).

had a prolonged hospital stay because of oxygen requirement and morphine withdrawal.

\section{Discussion}

Twenty cases of ALCARPA have been documented in the literature. ${ }^{1}$ However, there are only 2 reported cases of isolated ALCALPA., ${ }^{2,3}$ Our patient is one of the rare cases in which ALCALPA is associated with other congenital anomalies.
The embryology of this condition is unclear but can be explained by the theory of dual embryonic development of the coronary arteries from angioblastic buds in the truncus arteriosus, as was proposed by Doty and colleagues ${ }^{4}$ in a case of ALCARPA.

The diagnosis was missed on echocardiography, thus highlighting the fact that this condition is often a diagnostic challenge and even more so if there is an associated left-to-right shunt with pulmonary overload and hypertension that maintains normal coronary blood flow. This probably explains why she had no mitral insufficiency or any evidence of myocardial ischemia preoperatively.

Atik and associates ${ }^{2}$ reported one case of ALCALPA, and Sang and coworkers ${ }^{3}$ reported a child with the left circumflex artery arising from the LPA. Both of them presented with symptoms of congestive cardiac failure and were successfully treated with direct implantation. Atik and associates ${ }^{1}$ reported 4 cases of ALCARPA without associated defects but with intramural aortic trajectory, which facilitated the surgical correction. We did not find similar anatomy in our patient.

\section{Conclusion}

ALCALPA with a VSD and coarctation is an extremely uncommon lesion. The diaphragmatic hernia and PHT added complexity to the clinical problem, but the use of the newer and more effective methods of treating PHT allowed for a successful outcome.

\section{References}

1. Atik E, Barbero-Marcial M, Tanamati C, Kajita L, Ebaid M, Jatene A. anomalous origin of the left coronary artery from the right pulmonary artery with intramural aortic trajectory. Clinicosurgical diagnostic implications. Arq Bras Cardiol. 1999;73:181-90.

2. Atik E, Barbero Marcial M, Ikari NM, Kajita L, Machado D, Ebaid M, et al. Origin of left coronary artery from right and left pulmonary arteries-clinical, anatomico surgical and follow up evaluation of 3 cases. Arq Bras Cardiol. 1991;57:121-7.

3. Song JY, Lee JY, Kim S, Shim W, Kim WH, Kim Y. A rare case of anomalous left circumflex coronary artery from the left pulmonary artery. Int J Cardiol. 2003;88:305-7.

4. Doty DB, Chandramouli B, Schieken RE, Lauer RM, Ehrenhaft JL. Anomalous origin of the left coronary artery from the right pulmonary artery. J Thorac Cardiovasc Surg. 1976;71:787-96. 